\title{
Effects of Cl-914 in Congestive Heart Failure Due to Coronary Artery Disease or Idiopathic Cardiomyopathy
}

\author{
SUSAN TERRIS, MD, PhD, PATRICK D.V. BOURDILLON, MD, DAVID CHENG, MD, \\ JEFFREY LATTS, MD, STEVEN OLSEN, PhD, JOHN NICKLAS, MD, \\ and BERTRAM PITT, MD
}

The hemodynamic effects of $\mathrm{Cl}-914$, a phosphodiesterase inhibitor, were studied in 12 patients with left ventricular (LV) dysfunction who were undergoing diagnostic cardiac catheterization. $\mathrm{Cl}-914$ was infused intravenously at a rate of 0.8 to 7.0 $\mu \mathrm{g} / \mathrm{kg} / \mathrm{min}$ for 30 to 60 minutes; hemodynamic values were measured every 10 minutes. No effect was seen in the patient receiving $0.8 \mu \mathrm{g} / \mathrm{kg} / \mathrm{min}$. At infusion rates of 1.2 to $2.4 \mu \mathrm{g} / \mathrm{kg} / \mathrm{min}$, cardiac index increased by $14 \%(p<0.025)$. At infusion rates of 4.5 to $7.0 \mu \mathrm{g} / \mathrm{kg} / \mathrm{min}$, cardiac index increased by $21 \%$ ( $n=8$, difference not significant [NS]). Among 4 patients (group B) with an initial pulmonary artery wedge pressure greater than 20 $\mathrm{mm} \mathrm{Hg}$ and cardiac index less than 2.5 liters/ $\mathrm{min} / \mathrm{m}^{2}$, cardiac index increased by $50 \%$ ( $p$ $<0.001$ ); it did not change among the 4 patients with an initial pulmonary artery wedge pressure of less than $20 \mathrm{~mm} \mathrm{Hg}$ and cardiac index of more than 2.5 liters $/ \mathrm{min} / \mathrm{m}^{2}$ (group A). Although systemic vascular resistance decreased in all 8 patients by $26 \%(p<0.01)$, the reduction was greater in group $B(33 \%, p<0.01)$ than in group A $(16 \%$, NS). Peak +dP/dt increased in all 8 patients by $13 \%$ (p $<0.01$ ). Mean stroke work index increased from 29 \pm 15 to $34 \pm 13 \mathrm{~g}-\mathrm{m} / \mathrm{m}^{2}$; the double product fell from $101 \pm 31$ to $91 \pm 23$ (NS). In all 12 patients, a linear correlation between peak venous blood concentration and peak effect on cardiac index, systemic vascular resistance and pulmonary artery wedge pressure was observed. The increase in cardiac index associated with a decrease in systemic vascular resistance suggests that part of the favorable hemodynamic effect is attributable to afterload reduction. Nonetheless, the increase in peak $+\mathrm{dP} / \mathrm{dt}$ in all patients suggests that $\mathrm{Cl}-914$ also has a positive inotropic effect. This combination of effects may be of value in the treatment of severe congestive heart failure.

(Am J Cardiol 1986;58:596-600)
1

hosphodiesterase inhibitors have vasodilator and positive inotropic effects and are of value in the acute therapy of congestive heart failure $(\mathrm{CHF}) .{ }^{1-7}$ Like $\beta$ adrenergic agonists, ${ }^{8}$ phosphodiesterase inhibitors increase intracellular cAMP, enhance $\mathrm{Ca}^{++}$flux across the slow channel and $\mathrm{Ca}^{++}$release from the sarcoplasmic reticulum, ${ }^{9-12}$ exerting a combination of beneficial

From the Division of Cardiology, Department of Internal Medi* cine, University of Michigan Medical Center, and WarnerLambert/Parke Davis Pharmaceutical Research Division, Ann Arbor, Michigan. Manuscript received March 28, 1986; revised manuscript received May 8, 1986, accepted May 13, 1986.

Address for reprints: Patrick D.V. Bourdillon, MD, Division of Cardiology, Indiana University Hospital N562, 926 W. Michigan Street, Indianapolis, Indiana 46223. mechanical effects on myocardium. ${ }^{8}$ These drugs increase the peak force developed, the rate of force development and the relaxation velocity, thereby shortening total contraction time and maintaining diastolic function despite the tachycardia often associated with $\mathrm{CHF}$. Because they act distal to the $\beta$-adrenergic receptor, these agents are active even in patients with CHF who are relatively insensitive to catecholamines. ${ }^{13}$ Moreover, their prolonged use does not appear to be associated with development of tachyphylaxis, usually associated with $\beta$-adrenergic therapy. ${ }^{14}$

CI-914 is a new phosphodiesterase inhibitor selective for CAMP. ${ }^{15}$ It is equipotent with amrinone in increasing peak developed tension in rabbit right ventricular papillary muscle and guinea pig left atrium, and is 10 times more potent than amrinone in increas- 


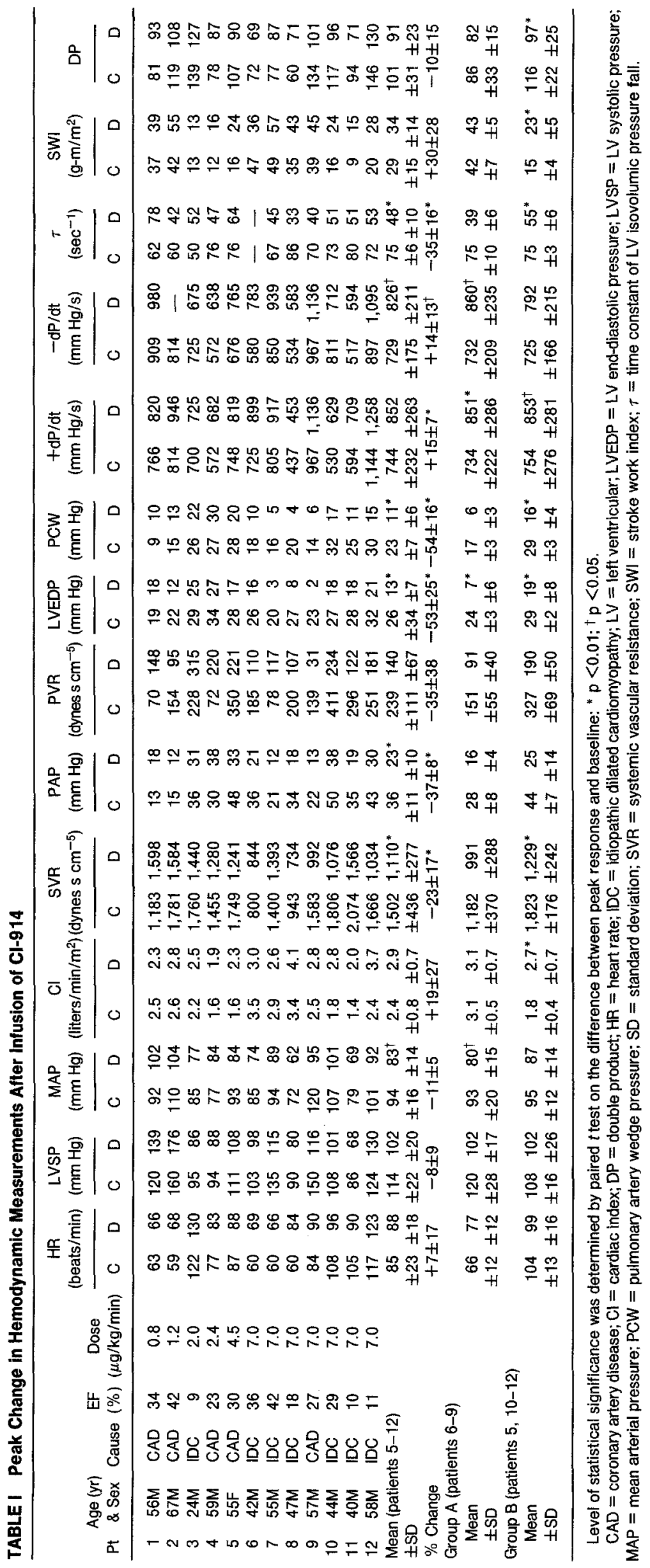


ing peak $+\mathrm{dP} / \mathrm{dt}$ after infusion into anesthetized dogs despite significant reduction of mean arterial pressure. ${ }^{15}$ As a pyridazinone derivative, chemically distinct from the bipyridines, amrinone and milrinone, it may not be associated with thrombocytopenia. ${ }^{16} \mathrm{We}$ report here the acute hemodynamic effects of CI-914 on patients with moderate to severe LV dysfunction.

\section{Methods}

Patients: Twelve patients with symptomatic LV dysfunction were studied at diagnostic cardiac catheterization (Table I). No patient had primary valvular disease, myocardial infarction in the past 2 weeks, unstable angina, left main coronary artery stenosis or clinically significant hepatic or renal disease. All had given informed consent to a study protocol approved by the University of Michigan Hospital Human Subject Review Committee.

Catheterization protocol: Topical nitrates, calcium channel blockers and afterload reducing agents, but not diuretic drugs or digoxin, were stopped 24 to 72 hours before cardiac catheterization. After routine right-sided cardiac catheterization and coronary arteriography, baseline hemodynamic variables (heart rate, LV pressure with a micromanometer-tip catheter, electronically differentiated $\mathrm{dP} / \mathrm{dt}$, pulmonary artery, pulmonary artery wedge, right atrial and arterial pressures, and cardiac output by thermodilution) were measured. CI-914 was administered to consecutive patients at rates of 0.8 (patient 1), 1.2 (patient 2), 2.0 (patient 3), 2.4 (patient 4), 4.5 (patient 5) and $7.0 \mu \mathrm{g} / \mathrm{kg} / \mathrm{min}$ (patients 6 through 12) for 60 minutes or until there was a $50 \%$ reduction in pulmonary artery wedge pressure,

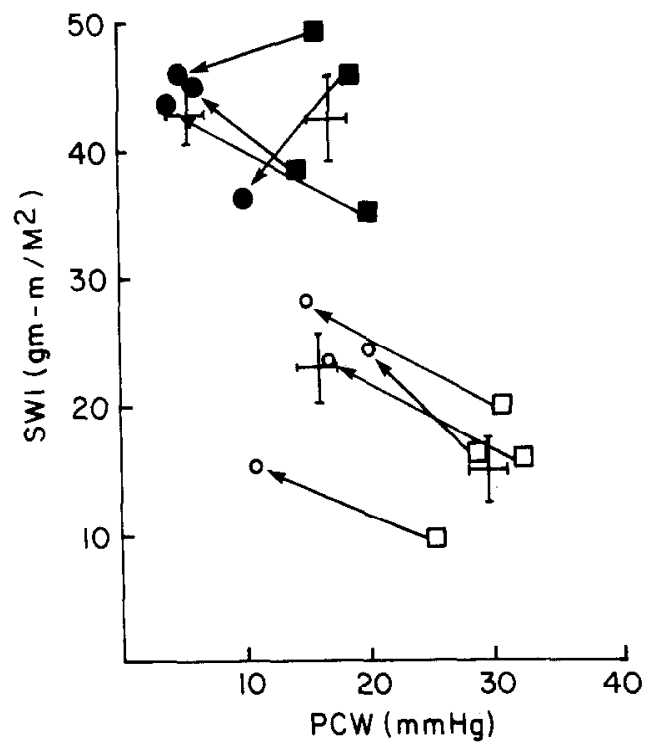

FIGURE 1. Dependence of change of stroke work index (SWI) on initial pulmonary artery wedge pressure (PCW). The mean \pm standard error of the mean of the initial and final PCW and SWI are shown. Closed squares indicate group A control; closed circles, group A after drug; open squares, group B control; and open circles, group $B$ after drug. a decrease in arterial pressure to less than $80 \mathrm{~mm} \mathrm{Hg}$ or a plateau in hemodynamic response. The infusions lasted for 60 minutes in patients 1 to 5,10 and 11; 50 minutes in patient $7 ; 40$ minutes in patients 6,9 and 12 ; and 30 minutes in patient 8 . Cardiac output and pressures were measured and femoral arterial and venous blood samples obtained from the side arms of the femoral introducer sheaths every 10 minutes during the infusion, for 30 minutes after termination of infusion and 2, 4 and 24 hours after infusion. CI-914 concentration was determined by high-pressure liquid chromatography. ${ }^{5}$

Analysis of data: Stroke work index was calculated as: (mean arterial pressure - LV end-diastolic pressure) $\times$ (stroke volume index] $\times 0.0136$. Double product was calculated as (LV systolic pressure) $\times$ (heart rate). The time constant of relaxation $(\tau)$ was calculat-
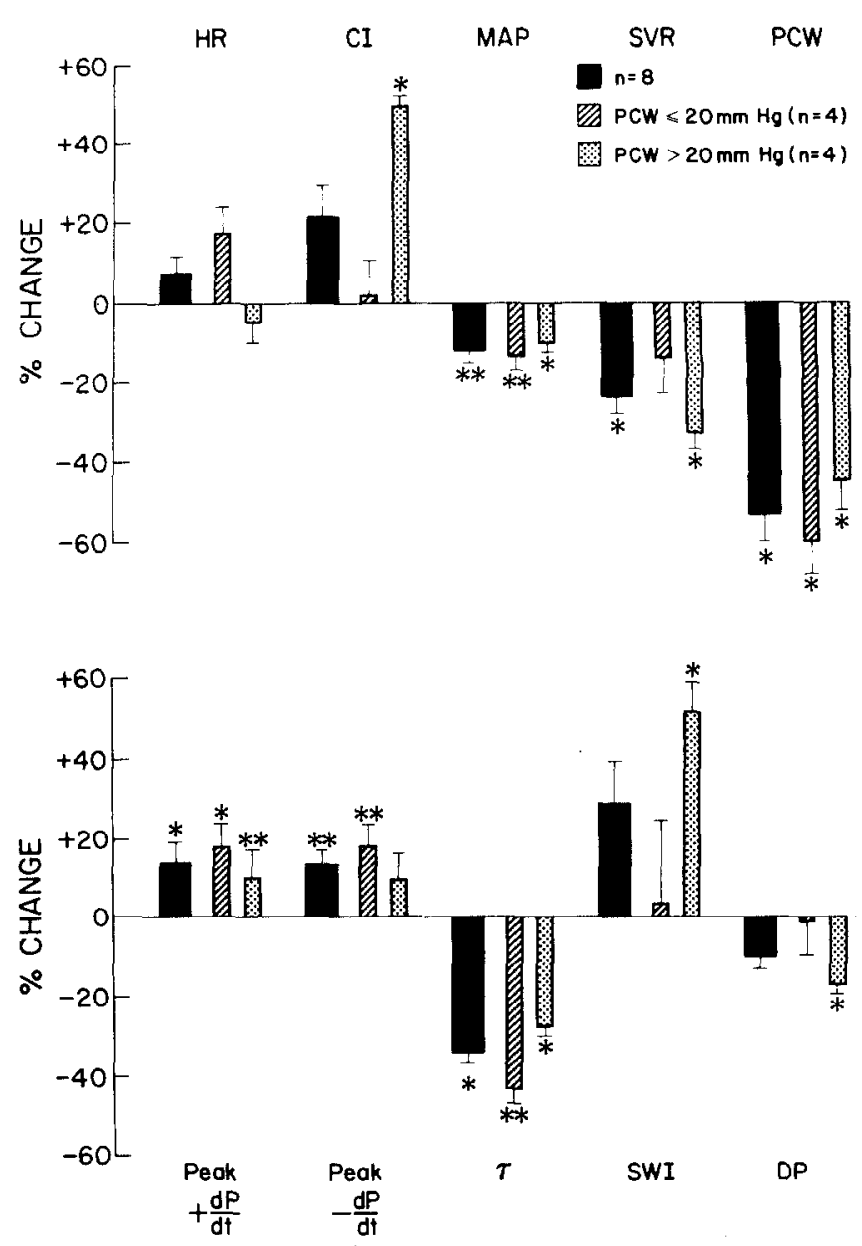

FIGURE 2. Systemic and cardiac effects of Cl-914. The peak effect of $\mathrm{Cl}-914$ on systemic and cardiac hemodynamic varlables are expressed as mean percent change from baseline \pm standard error. The hemodynamic effects on patients in groups $A$ and $B$ are shown. Level of statistical significance was determined by paired $t$ test on the difference between peak change and baseline. " $p<0.01$; * $p$ $<0.05 . \mathrm{Cl}=$ cardlac index; $\mathrm{DP}=$ double product; $\mathrm{HR}=$ heart rate; MAP $=$ mean arterial pressure; $P C W=$ pulmonary capillary wedge pressure; SVR = systemic vascular resistance; $\mathbf{S W I}=$ stroke work index; $\tau=$ time constant of relaxation. 
ed as the inverse slope of a plot of log pressure vs time during isovolumic relaxation beginning at the time of peak $-\mathrm{dP} / \mathrm{dt} \cdot{ }^{17}$ Because the hemodynamic response of patients receiving between 1.2 and $2.4 \mu \mathrm{g} / \mathrm{kg} / \mathrm{min}$ differed from that of patients receiving a larger dose, these patients were analyzed separately. Data are expressed as peak response (Table I). In general, the peak change in all hemodynamic values occurred toward the end of the infusion.

\section{Results}

No significant hemodynamic effects were observed at an infusion rate of $0.8 \mu \mathrm{g} / \mathrm{kg} / \mathrm{min}$. At infusion rates of 1.2 to $2.4 \mu \mathrm{g} / \mathrm{kg} / \mathrm{min}$, cardiac index increased by $14 \%$ ( $\mathrm{n}=3, \mathrm{p}<0.025$ ), and systemic vascular resistance was reduced to the same degree $(n=3, p<0.05)$. Peak $+\mathrm{dP} / \mathrm{dt}$ did not increase significantly (Table I). At infusion rates of 4.5 to $7.0 \mu \mathrm{g} / \mathrm{kg} / \mathrm{min}$, cardiac index of the 8 patients increased from $2.4 \pm 0.8$ to $2.9 \pm 0.7$ liters $/ \mathrm{min} / \mathrm{m}^{2}$ and stroke work index from $29 \pm 15$ to 34 $\pm 14 \mathrm{~g}-\mathrm{m} / \mathrm{m}^{2}$; however, these effects were not uniform. In 4 patients with a pulmonary artery wedge pressure of less than $20 \mathrm{~mm} \mathrm{Hg}$ (patients 6 through 9 , group A), cardiac index and stroke work index did not change significantly (from $3.1 \pm 0.5$ to $3.1 \pm 0.7$ liters $/ \mathrm{m} / \mathrm{m}^{2}$ and from $42 \pm 7$ to $43 \pm 5 \mathrm{~g}-\mathrm{m} / \mathrm{m}^{2}$, respectively) (Fig. 1 and 2 , Table I). In contrast, in 4 patients with a pulmonary artery wedge pressure of morc than $20 \mathrm{~mm} \mathrm{Hg}$ (patients 5, 10, 11 and 12, group B), both cardiac and stroke work indexes increased (from $1.8 \pm 0.4$ to 2.7 \pm 0.7 liters $/ \mathrm{min} / \mathrm{m}^{2}, \mathrm{p}<0.01$, and $15 \pm 4$ to $23 \pm 5$ $\mathrm{g}-\mathrm{m} / \mathrm{m}^{2}, \mathrm{p}<0.01$ ]. In group B systemic vascular resistance fell more than in group A ( $32 \%$ vs $16 \%, p<0.01$ ), as did LV end-diastolic pressure $(71 \%$ vs $36 \%$, p $<0.01)$. The double product decreased more among patients in group B $[16 \%, \mathrm{p}<0.01\}$ than in group A [4\%, difference not significant [NS]\}. Ejection fraction was $30 \pm 11 \%$ in group $A$ and $20 \pm 11 \%$ in group $\mathrm{B}$ (NS).

Peak $+\mathrm{dP} / \mathrm{dt}$ increased from $744 \pm 232$ to $852 \pm 263$ $\mathrm{mm} \mathrm{Hg} / \mathrm{s}$ in the 8 patients in groups $\mathrm{A}$ and $\mathrm{B}(\mathrm{p}<0.01)$, despite variable changes in heart rate and despite a decrease in diastolic arterial pressure. Peak $-\mathrm{dP} / \mathrm{dt}$ rose from $729 \pm 175$ to $826 \pm 211 \mathrm{~mm} \mathrm{Hg} \mathrm{s}^{-1}$ [n $=7$, p $<0.05$ ), and $\tau$ was reduced from $75 \pm 6$ to $48 \pm 10 \mathrm{~s}^{-1}$ ( $\mathrm{n}$ $=8, \mathrm{p}<0.01$.

Among all 12 patients receiving the drug, the peak increase in cardiac index correlated with peak venous drug concentration (Fig. 3) $(r=0.58, p<0.01)$. There was a better correlation of peak venous plasma level with the decrease in pulmonary artery wedge pressure $(\mathrm{r}=-0.69, \mathrm{p}<0.01)$ than with the decrease in systemic vascular resistance $(\mathrm{r}=-0.52, \mathrm{p}<0.01)$. The peak values of other parameters (pulmonary artery pressure, peak $+\mathrm{dP} / \mathrm{dt}$ and $-\mathrm{dP} / \mathrm{dt}$, and $\tau$ ) did not significantly correlate with venous plasma level. The change in venous levels of the drug after infusion did not follow first-order kinetics. In 2 patients with venous drug concentrations of less than $100 \mathrm{ng} / \mathrm{ml}$, the drug concentration dropped to half its initial value at the end of infusion over the next 2 hours. In 10 patients with venous drug levels above $100 \mathrm{ng} / \mathrm{ml}$, drug concentration fell to half its initial value after 5 hours.

\section{Discussion}

These findings suggest that CI-914 administered at rates of $1.2 \mu \mathrm{g} / \mathrm{kg} / \mathrm{min}$ or more improves the hemodynamic state of patients with severe CHF primarily by reducing systemic vascular resistance. Among patients who responded, systemic vascular resistance fell by $33 \%, \mathrm{LV}$ end-diastolic pressure remained optimal, and, consequently, stroke volume index increased $32 \%$. Among patients who did not respond, the initial systemic vascular resistance was not significantly elevated; LV end-diastolic pressure decreased to levels not optimal to maintain LV filling; and stroke volume index decreased by $16 \%$. The fact that the group with a

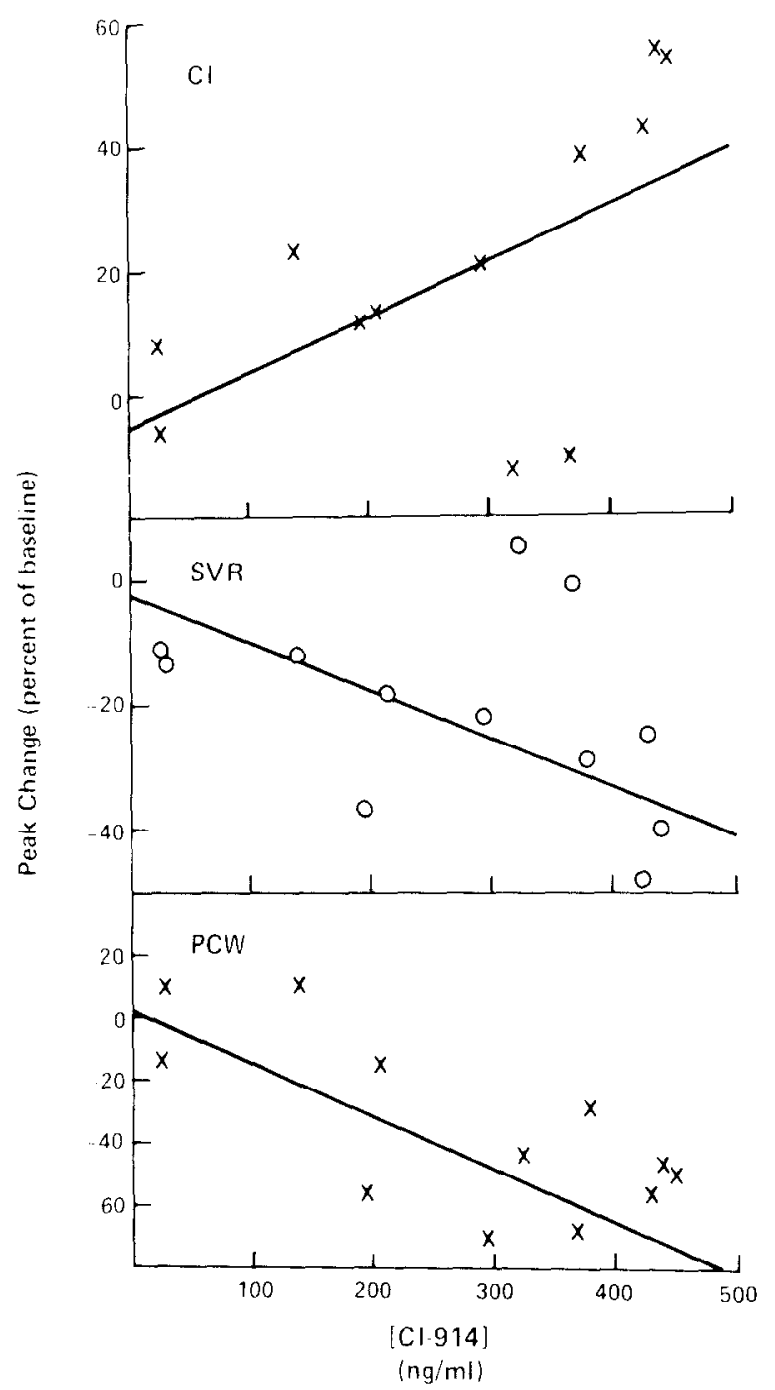

FIGURE 3. Peak changes of cardiac index (CI), systemic vascular resistance (SVR) and pulmonary artery wedge pressure (PCW) as a percent of the baseline value vs peak venous plasma concentration of $\mathrm{Cl}-914$. Regression equations are: Percent change of $\mathbf{C l}=\mathbf{0 . 0 9 2}$ $[\mathrm{Cl}-914]-5.46 ; r=0.58 ; n=12 ; p<0.01$. Percent change of systemlc vascular resistance $=-0.60[\mathrm{Cl}-914]-1.46 ; \mathrm{r}=0.52 ; \mathrm{n}$ $=12 ; p<0.05 . \%$ change of pulmonary artery wedge $=-0.13[\mathrm{Cl}-$ $914]+0.067 ; r=-0.67 ; n=12 ; p<0.01$. 
worse ejection fraction (group B) responded better to the drug underscores the value of the drug as a vasodilator; those with a poorer ejection fraction had an initial hemodynamic state that was more responsive to vasodilatation than those of the nonresponders.

The positive inotropic effect of CI-914 contributed to its beneficial effect. Peak $+\mathrm{dP} / \mathrm{dt}$ increased in all patients receiving at least $1.2 \mu \mathrm{g} / \mathrm{kg} / \mathrm{min}$, without an effect on heart rate or on arterial diastolic pressure, variables that may themselves alter peak $+\mathrm{dP} / \mathrm{dt}^{18}$ and despite a significant reduction in LV end-diastolic pressure, suggesting an upward shift in the Starling curve. Systolic function may have improved as a result of improved diastolic function, as observed with milrinone treatment. ${ }^{6}$ These effects are comparable to those reported by Jafri et $\mathrm{al}^{7}$ and those reported for other phosphodiesterase inhibitors. ${ }^{2-5}$

The reduction in the systolic double product observed among responders reflects a reduction in myocardial oxygen consumption. ${ }^{19}$ The effect of reduction of the range of working $\mathrm{LV}$ pressure on myocardial oxygen consumption more than offset the higher energy cost of an increase in volume work. ${ }^{20,21}$

Thus, similar to other vasodilators, CI-914 converts pressure work to volume work and thereby improves cardiac index while reducing myocardial oxygen consumption.

Although CI-914 and other phosphodiesterase inhibitors have acute beneficial effects in patients with $\mathrm{CHF}$, the long-term effectiveness and safety must be questioned. ${ }^{22,23}$ Nonetheless, the results of the present investigation and of studies of other phosphodiesterase inhibitors suggest that these agents will play an important role in the therapy of patients with severe LV dysfunction.

\section{References}

1. Mikulic E, Cohn JN, Franciosa JA. Comparative hemodynamic effects of inotropic and vasodilator drugs in severe heart failure. Circulation 1977 ; 56:528-533.

2. Baim DS, McDowell AV, Cherniles J, Monrad ES, Parker JA, Edelson J Braunwald E. Grossman W. Evaluation of a new bipyridine inotropic agentmilrinone-in patients with severe congestive heart failure. $N$ Engl I Med 1983;309:748-756.

3. Benotti JR, Grossman W, Braunwald E, Carabello B. Effects of amrinone on myocardial energy metabolism and hemodynamics of patients with severe congestive heart failure due to coronary artery disease. Circulation 1980
62:28-34.

4. Maskin CS, Sinoway L, Chadwick D, Sonnenblick EH, LeJemtel TH. Sustained hemodynamic and clinical effects of a new cardiotonic agent, WIN 47203 , in patients with severe congestive heart failure. Circulation 1983; 67:1065-1067.

5. Kereiakes D, Chatterjee K, Parmley WW, Atherton B, Curran D, Kereiakes A, Spangenberg R. Intravenous and oral MDL 17043 (a new inotropic vasodilutor ugent) in congestive heart fuilure: hemodynamic and clinical evaluation in 38 patients. IACC 1984;4;884-889.

6. Monrad ES, McKay RG, Baim DN, Colucci WS, Fifer MA, Heller GV, Royal AD, Grossman W. Improvement in indices of diastolic performance in patients with congestive heart failure treated with milrinone. Circulation 1984;70:1030-1037.

7. Jafri S, Burlew BS, Goldberg D, Rogers A, Goldstein S. Ilemodynamic effects of a new phosphodiesterase inhibitor (CI-914) for congestive heart failure. Am / Cardiol 1986;57:254-259.

8. Scholz HI. Mechanism of action of inotropic drugs. IACC 1984;4:389-397. 9. Colucci WS, Wright RF, Braunwald E. New positive inotropic agents in the treatment of congestive heart failure. $N$ Engl J Med 1986;314:290-299,349358.

10. Korth M. Effects of several phosphodiesterase inhibitors on guinea pig myocardium. Arch Pharmacol 1978;302:77-86.

11. Honerjagger $P$, Schafer-Korting $M$, Reiter M. Involvement of cyclic AMP in the direct inotropic acion of amrinone: biochemical and functional evidence. Naunyn-Schmiedebergs Arch Pharmacol 1981;318:112-120.

12. Drummond GI, Severson DC. Cyclic nucleotides and cardiac function. Circ Res 1979;44:145-153.

13. Bristow MR, Ginsburg R, Minobe W, Cubicciotti RS, Sageman WS, Lurie K, Billingham ME, I Iarrison DC, Stimson ED. Decreased catecholamine sensitivity and beta adrenergic receptor density in failing human hearts. $N$ Engl Med 1982;216:205-211.

14. Malakoff RF, Curfman GD, Wynne J, Neill J, Draunwald D. Inotropic effect of Amrinone on severe congestive heart failure: lack of attenuation with sequential doses (abstr). Am J Cardiol 1980;45:433.

15. Investigational Brochure: RnX-720-00075. Ann Arbor, MI: Warner-Lambert/Parke Davis. Pharmaceutical Research Division, 1983.

16. Wilmshurst PT, Al-Hasani SFA, Semple MJ, Hamblin AS, Kody PG, Lucas GF, Savidge GF, Webb-Peploe MM. The effects of Amrinone on platelet count, survival and function in patients with congestive heart failure. Br $/ \mathrm{Clin}$ Pharmacol 1984;17:317-324.

17. Weiss JB, Frederiksen JW, Weisfeldt JL. Hemodynamic determinants of the time course of fall in the canine left ventricular pressure. J Clin Invest 1976:58:751-760.

18. Barnes GE, Horwitz LD, Bishop VS. Reliability of the maximum derivatives of left ventricular pressure and internal diameter as indices of the inotropic state of the depressed myocardium. Gardiovasc Res 1979;13:652662.

19. Baller D, Bretschneider JH, Hellige G. Validity of myocardial oxygen consumption parameters. Clin Cardiol 1979;2:317-327.

20. Rooke GA, Feigl EO. Work as a correlate of canine left ventricular oxygen consumption and the problem of catecholamine oxygen wasting. Circ Res 1982;50:273-286.

21. Suga $H$, Hisano R, Hiraa $S$, Hayashi T, Ninomiya I. Mechanism of higher oxygen consumption rate: pressure-loaded vs. volume-loaded heart. Am J Physiol 1982;242:H942-H948.

22. DiBianco R, Shabetai R, Silverman BD, Leier CV, Benotti JR, Amrinone Multicenter Study Investigators: Oral amrinone for the treatment of chronic congestive heart failure: results of a multi-center double-blind and placebocontrolled withdrawal study. JACC 1984;4:855-866.

23. Packer M, Medina N, Yushak M. Hemodynamic and clinical limitations of long-term inotropic therapy with amrinone in patients with severe chronic heart failure. Circulation 1984;70:1038-1047. 